\title{
Preoperative Colonoscopic Tattooing Using a Direct Injection Method with Indocyanine Green for Localization of Colorectal Tumors: An Efficacy and Safety Comparison Study
}

\author{
Young Jin Kim, M.D. ${ }^{1}$, Ji Won Park, M.D., Ph.D. ${ }^{1,2}$, Han-Ki Lim, M.D. ${ }^{1}$, Yoon-Hye Kwon, M.D. ${ }^{1}$, Min Jung Kim, M.D. ${ }^{1,2}$, \\ Eun Kyung Choe, M.D., Ph.D. ${ }^{1,3}$, Sang Hui Moon, M.D., Ph.D. ${ }^{1}$, Seung-Bum Ryoo, M.D., Ph.D. ${ }^{1,2}$, Seung-Yong Jeong, M.D., Ph.D. ${ }^{1,2}$, \\ Kyu Joo Park, M.D., Ph.D. ${ }^{1}$ \\ ${ }^{1}$ Department of Surgery, Seoul National University College of Medicine, ${ }^{2}$ Cancer Research Institute, Seoul National University College of Medicine, \\ ${ }^{3}$ Healthcare Research Institute, Seoul National University Hospital Healthcare System Gangnam Center, Seoul, Korea
}

Purpose: Endoscopic tattooing is used to mark colorectal lesions for subsequent surgery. As a tattooing agent, India ink has been widely used but is not currently available in Korea. Indocyanine green (ICG) can be applied as an alternative agent. However, studies on colonoscopic tattooing by the direct injection of indocyanine green are lacking. This study aimed to compare the efficacy and safety between an ICG direct injection method and an India ink saline test injection method.

Methods: A total of 227 patients who underwent preoperative endoscopic tattooing for colorectal neoplasm (149 patients in the ICG direct injection group and 78 patients in the India ink saline test injection group) were included in the study. The efficacy of the two methods was compared by visualization and safety was compared by evaluating the perioperative tattooing complications.

Results: The visualization of lesions in the ICG group was not different from that of the India ink group ( $p=0.42,96.0 \%$ vs $98.7 \%$, respectively). Only one patient in the ICG group had abdominal pain related to tattooing, but no complications developed in the India ink group.

Conclusion: Considering the good visualization and low complication rate, the direct injection of ICG can be used as an alternative tattooing method.

Keywords: Colorectal neoplasm, Colonoscopy, Tattooing, Indocyanine green, Ink
Received August 31, 2020

Revised 1st October 21, 2020 2nd October 31, 2020 3rd November 4, 2020

Accepted November 4, 2020

Corresponding author

Ji Won Park

Department of Surgery and Cancer Research Institute, Seoul National University College of Medicine, 101 Daehak-ro, Jongno-gu, Seoul 03080, Korea

Tel: $+82-2-2072-2325$

Fax: +82-2-766-3975

E-mail: sowisdom@gmail.com ORCID:

https://orcid.org/0000-0003-0046-8175

Copyright @ 2020 The Journal of Minimally Invasive Surgery. All rights reserved.

This is an Open Access article distributed under the terms of the Creative Commons Attribution Non-Commercial License (http:/ creativecommons.org/licenses/by-nc/4.0/) which permits unrestricted non-commercial use, distribution, and reproduction in any medium, provided the original work is properly cited.

\section{INTRODUCTION}

Primary tumor resection is the main treatment for colorectal cancer. For the optimal resection of colorectal neoplasms, identifying the exact location of the lesion is essential. Unlike advanced colorectal neoplasms, early colorectal cancer or adenoma cannot be easily detected during surgery. Moreover, the detection of these lesions can be more difficult during minimally invasive surgery because of the lack of tactile sensations to locate the tumor. ${ }^{1}$ Inaccurate localization of the lesion may lead to an unexpected procedural change during surgery or resection of the wrong segment.

The rates of laparoscopic surgery for colorectal cancer have increased in Korea, ${ }^{2}$ as has the proportion of colorectal cancer detected early. ${ }^{3}$ With these trends, the need to locate primary colorectal lesions has also increased.

Several methods have been used for the localization of colorectal neoplasms. ${ }^{4,5}$ Colonoscopic tattooing, colonoscopic metallic 
clipping, colon study, and computed tomography colonography can be used depending upon the clinical situation. Among these methods, colonoscopic tattooing is one of the popular approaches because it can accurately localize lesions and detect small or nonpalpable lesions.

Methylene blue, indigo carmine, indocyanine green (ICG), and India ink can be used for colonoscopic tattooing. An initial study reported that ICG was effective based on persistency and tolerable adverse reactions. ${ }^{6}$ However, a limitation of ICG is the tendency to fade with time. ${ }^{7}$ A randomized animal study showed that India ink was superior to ICG in terms of durability. ${ }^{8}$ Currently, India ink is the most effective and widely used agent for tattooing.

For tattooing, India ink has been supplied as a prepackaged sterile suspension consisting of purified carbon particles. However, this premixed package is not currently available in Korea. Thus, a recent study on endoscopic ICG tattooing investigated the usefulness of ICG using a saline test injection method. ${ }^{9}$

In the saline test injection method, the saline is injected into the submucosal layer before and after tattooing, and was shown to improve the accuracy and safety of India ink tatooing. ${ }^{10}$ However, this method requires more manipulations than the conventional direct injection method. The direct injection method can be used with ICG because ICG is a liquid solution, which does not contain particles like those in India ink. However, studies comparing the outcomes between colonoscopic tattooing using the direct injection of ICG and the India ink method are still lacking. This study aimed to compare the efficacy and safety between the direct injection method of ICG and the saline test injection method using India ink.

\section{MATERIALS AND METHODS}

This study included patients who underwent primary tumor resection after preoperative endoscopic tattooing for colorectal neoplasm at Seoul National University Hospital Study from January 2009 to December 2017. The protocol was approved by the
Seoul National University Hospital Institutional Review Board (IRB No.: H-1907-043-1046). Patients in whom both agents were used were excluded from the study.

The patients were divided into two groups according to the tattooing agent used, the ICG group and the India ink group. India ink was used before October 2013, and after that, ICG was used as a tattooing agent. In the ICG group, the endoscopists injected 0.5 cc of ICG (Diagnogreen Injection, Daiichi Sankyo Co., Ltd., Tokyo, Japan) directly, without saline loading, into the submucosal layer using a 23-gauge injection needle (Olympus Medical Systems Co, Ltd., Tokyo, Japan) (Fig. 1). In the cases of ICG, tattooing was usually performed a day before operation day. If there was a public holiday or weekend just before operation day, tattooing was performed a day before a public holiday or weekend. In the India ink group, 1 to $1.5 \mathrm{ml}$ of India ink (SPOT Endoscopic Marker, GI Supply, Camp Hill, PA, USA) was injected into the submucosal layer using the same gauge injection needle, after $1 \mathrm{ml}$ of saline was injected to form a proper submucosal elevation. An additional $1 \mathrm{ml}$ of saline was injected to flush out the remaining agents. ${ }^{10}$ In both group, the agents were injected at three circumferential sites $120^{\circ}$ apart around the tumor site.

The data were collected retrospectively from the surgical and anesthesia records, pathologic reports, and medical charts. Visualization was based on the serosal color changes and localization of the main lesion. The visualization was identified in the records of the operation notes and gross pathologic images. The information on intraoperative colonoscopy events, complications from tattooing, and the perioperative outcomes were collected. The $\chi^{2}$ test or Fisher's extract test and the t-test were used to compare the characteristics and outcomes of the two groups using SPSS software (SPSS Inc., Chicago, IL, USA). $p$ values of less than 0.05 were considered significant.

\section{RESULTS}

Two hundred-thirty patients underwent primary tumor resection after tattooing. Three cases were excluded. One patient
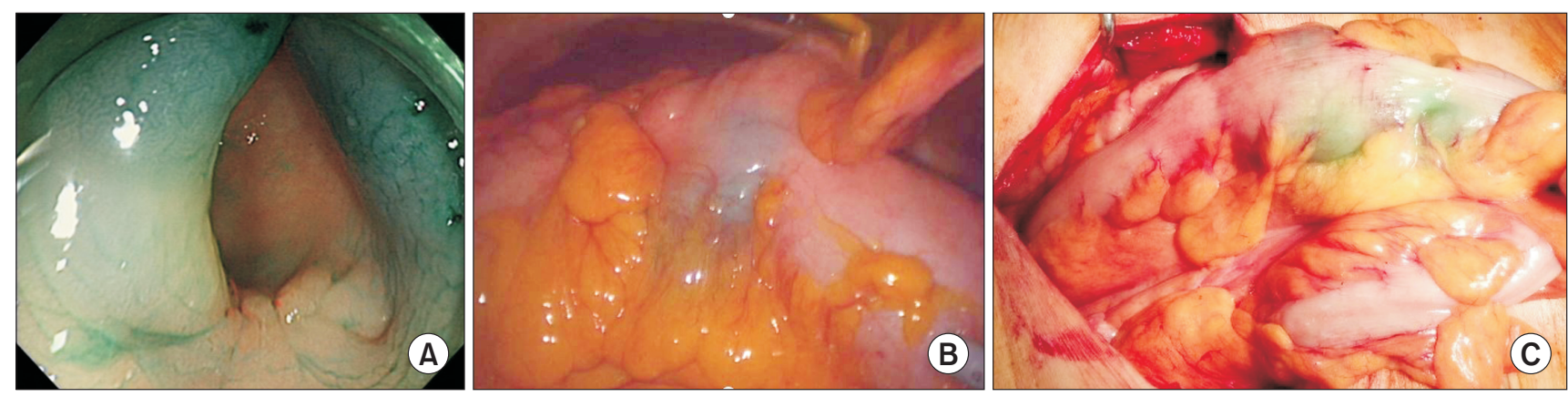

Fig. 1. (A) Endoscopic view after tattooing with indocyanine green. (B) Serosal appearance during laparoscopic surgery after tattooing with indocyanine green. (C) Serosal appearance during open surgery after tattooing with indocyanine green. 
was tattooed twice with ICG and both agents were used in two patients. Finally, a total of 227 patients were included in this study, 149 patients in the ICG group and 78 patients in the India ink group. The baseline characteristics are shown in Table 1. There was no difference between the two groups in terms of

Table 1. Baseline characteristics between indocyanine green and India ink group

\begin{tabular}{|c|c|c|c|}
\hline & $\underset{(n=149)}{\text { ICG }}$ & $\begin{array}{c}\text { India ink } \\
(n=78)\end{array}$ & $p$ value \\
\hline Age (year, Mean \pm SD) & $62.4 \pm 9.8$ & $60.1 \pm 10.6$ & 0.118 \\
\hline Gender & & & 0.666 \\
\hline Male & $91(61.1)$ & $52(66.7)$ & \\
\hline Female & $58(38.9)$ & $26(33.3)$ & \\
\hline $\mathrm{BMI}\left(\mathrm{kg} / \mathrm{m}^{2}, \mathrm{Mean} \pm \mathrm{SD}\right)$ & $24.3 \pm 2.9$ & $24.2 \pm 2.9$ & 0.716 \\
\hline Previous endoscopic treatment & & & 0.076 \\
\hline Yes & $49(32.8)$ & $35(44.8)$ & \\
\hline No & $100(67.2)$ & $43(55.2)$ & \\
\hline ASA classification & & & 0.319 \\
\hline $\mid / \|$ & $141(94.6)$ & $77(97.4)$ & \\
\hline III/IV & $8(5.4)$ & $2(2.6)$ & \\
\hline Tumor stage & & & 0.594 \\
\hline $0 / 1$ & $91(61.1)$ & $49(62.8)$ & \\
\hline 2 & $22(14.78)$ & $9(11.6)$ & \\
\hline 3 & $34(22.8)$ & $17(21.8)$ & \\
\hline 4 & $2(1.3)$ & $3(3.8)$ & \\
\hline Histologic type & & & 0.890 \\
\hline Low grade & $130(86.1)$ & $69(87.3)$ & \\
\hline High grade & $7(4.6)$ & $4(5.1)$ & \\
\hline Other & $12(7.9)$ & $5(6.3)$ & \\
\hline Tumor lesion & & & 0.024 \\
\hline Right-side colon & $42(28.2)$ & $11(14.1)$ & \\
\hline Left-side colon & $68(45.6)$ & $49(62.8)$ & \\
\hline Rectum & $39(26.2)$ & $18(23.1)$ & \\
\hline Operative type & & & 0.005 \\
\hline Laparoscopic & $90(60.4)$ & $62(79.5)$ & \\
\hline Open & $59(39.6)$ & $16(20.5)$ & \\
\hline $\begin{array}{l}\text { Interval between tattooing and } \\
\text { operation (day, Mean } \pm S D \text { ) }\end{array}$ & $1.4 \pm 0.9$ & $6.2 \pm 7.4$ & 0.000 \\
\hline
\end{tabular}

Values are presented as number (\%). Histologic type-other: 13 intramucosal carcinoma, 1 adenosquamous carcinoma, 2 adenocarcinoma (unknown differentiation), 1 neuroendocrine carcinoma. ICG = indocyanine green; BMI = body mass index; $\mathrm{ASA}=$ American Society of Anesthesiologists. age, gender, body mass index, previous endoscopic treatment, ASA(American Society of Anesthesiologists) classification, tumor stage, and histologic type. The India ink group had more left-sided colon tumors than the ICG group. Laparoscopic resection was performed more often in the India ink group than in the ICG group. The interval between tattooing and surgery was shorter in the ICG group than in the India ink group.

Table 2 shows the results of endoscopic tattooing. There was no difference between the ICG and India ink groups in visualization ( $96.0 \%$ vs $98.7 \%$, respectively, $p=0.42$ ). One patient in the ICG group underwent intra-operative endoscopy because of the non-visualization of a tattooed lesion. The rate of visualization was not significantly different between ICG and India ink in both open and laparoscopic surgery group (Open: $98.3 \%$ vs $100 \%$, $p=1.00$; Laparoscopic: $94.4 \%$ vs $98.3 \%, p=0.40$ ). There was one complication in the ICG group, which was mild abdominal pain that improved with conservative treatment. There was no intraoperative endoscopy or tattooing complications in the India ink group.

The perioperative outcomes are shown in Table 3. The mean operation time and hospital stay were not different between the two groups. There was no mortality in either group within 30

Table 2. The results of endoscopic tattooing between indocyanine green and India ink and group

\begin{tabular}{lccc}
\hline & $\begin{array}{c}\text { ICG } \\
(\mathrm{n}=149)\end{array}$ & $\begin{array}{c}\text { India ink } \\
(\mathrm{n}=78)\end{array}$ & $p$ value \\
\hline Visualization & $144(96.0)$ & $77(98.7)$ & 0.42 \\
$\quad$ Open & $58(98.3)$ & $17(100)$ & 1.00 \\
$\quad$ Laparoscopic & $85(94.4)$ & $60(98.3)$ & 0.40 \\
Intraoperative endoscopy & $1(0.6)$ & $0(0)$ & 1.00 \\
Complication of tattooing & $1(0.6)$ & $0(0)$ & 1.00 \\
\hline
\end{tabular}

Values are presented as number (\%). ICG = indocyanine green.

Table 3. Postoperative outcomes between indocyanine green and India ink group

\begin{tabular}{lccc} 
& $\begin{array}{c}\text { ICG } \\
(\mathrm{n}=149)\end{array}$ & $\begin{array}{c}\text { India ink } \\
(\mathrm{n}=78)\end{array}$ & $p$ value \\
\hline $\begin{array}{c}\text { Operative time (min, } \\
\text { mean } \pm \text { SD) }\end{array}$ & $137.9 \pm 74.4$ & $141.9 \pm 97.4$ & 0.747 \\
$\begin{array}{l}\text { Overall postoperative } \\
\text { complication }\end{array}$ & $32(21.4)$ & $11(14.1)$ & 0.178 \\
$\begin{array}{l}\text { Hospital stay (day, mean } \pm \mathrm{SD}) \\
\begin{array}{l}\text { Mortality within post } \\
\text { operation 30 days }\end{array}\end{array}$ & $8.6 \pm 3.8$ & $8.0 \pm 7.6$ & 0.413 \\
\hline
\end{tabular}

Values are presented as number (\%). ICG = indocyanine green. 
days after surgery.

\section{DISCUSSION}

This study demonstrated that the direct injection of ICG could be a safe and effective approach for colorectal endoscopic tattooing. Compared with the current gold standard method (a saline test injection method with India ink), the direct ICG injection method had good and non-inferior visualization (96.0\%) and mild complications from tattooing (0.6\%). A systemic review reported no differences in the incidence of localization errors between India ink and ICG tattooing (7.7\% vs 3.6\%, respectively). ${ }^{5}$ Miyoshi et al. ${ }^{7}$ also reported that ICG could be an alternative tattooing agent to India ink. However, the visualization time of ICG was limited and did not persist over eight days in most cases. Another study reported that the visualization rate was only $40 \%$ when ICG tattoos were made more than three days before surgery. ${ }^{9}$ Because of this limitation of ICG, most patients in the ICG group underwent surgery within three days after tattooing in this study. In contrast to ICG, India ink persists semi-permanently, so does not have a time limitation between tattooing and surgery.

The saline test injection method was reported to improve the accuracy of localization and lower the incidence of adverse events." This technique also has the advantage of reducing the leakage of agents. A study using this method with ICG showed good visualization (93.5\%) and no complications. ${ }^{9}$ Because ICG has no particles, unlike India ink, it can be manipulated more easily than India ink and injected directly into the submucosa without a saline test injection. The advantage of the direct injection method is simple handling without the need to change syringes. Our study is meaningful in that it demonstrated the feasibility of the direct injection method using ICG for colorectal tattooing.

There were no severe complications related to tattooing in this study. One patient in the ICG group felt abdominal pain upon tattooing, but there were no other symptoms or sequelae after tattooing and no abnormal findings during surgery. Other studies have reported low complication rates related to tattooing. ${ }^{12}$ Nizam et al. ${ }^{13}$ reviewed studies using India ink tattooing, and reported only a $0.22 \%$ complication rate. The complications included peritonitis and inflammatory bowel disease, and it was clear that leakage of the agent beyond the serosa of the colon could present problems. ${ }^{12,13}$ In other ICG studies in animals and humans, there were no major complications associated with tattooing. ${ }^{7,8,14}$ Because of the nature of tattooing agents, India ink contaminates operative field with carbon pigmentation when it is spilled into peritoneal cavity. ${ }^{12,15}$ Even though ICG is sustainable in the colorectal tissue for a limited time, ICG is less likely to disturb surgical field in the case of leakage. This is one of the benefits when using ICG as a tattooing agent. However, this study did not investigate the exact rates of leakage because of the lack of data.

Other approaches for the localization of colorectal tumors, such as endoscopic tattooing with autologous blood and endoscopic marking with near-infrared fluorescent clips, have been suggested. ${ }^{16,17}$ The visualization of tattooing using $6 \sim 12 \mathrm{ml}$ of autologous blood was good (92.2\%). Three patients (5.9\%) experienced tattooing-related adverse events. The visualization of marking with fluorescent clips was also good (94.1\%) and there were no adverse effects related to clip marking and detection.

In this study, the lesions were detected as color changes of green in serosa by only naked eyes. ICG can be more sensitively detected using ICG fluorescence cameras. Further study using the ICG fluorescence camera will give more insight for the precise detection of tattooing lesions.

There were some limitations to this study. First, the present study was limited by its retrospective design. There were differences between the two groups in clinical characteristics (tumor location and operation type). Second, the period of study was different between the two groups. The ICG group had more recent cases than the India ink group. Thus, the endoscopists' techniques may have differed between the two study periods. Third, there was no specific data of the leakage of tattooing agents in this study. However, this study had the strengths of including a relatively large number of patients and comparing a new approach with the conventional gold standard.

\section{CONCLUSION}

In conclusion, a direct injection method with ICG can be used as an alternative tattooing method for colorectal tumors when it is performed within 3 days before surgery.

\section{ORCID}

Young Jin Kim, https://orcid.org/0000-0002-4900-9933

Ji Won Park, https://orcid.org/0000-0003-0046-8175

Han-Ki Lim, https://orcid.org/0000-0001-9320-5328

Yoon-Hye Kwon, https://orcid.org/0000-0003-2501-0590

Min Jung Kim, https://orcid.org/0000-0002-3105-9633

Eun Kyung Choe, https://orcid.org/0000-0002-7222-1772

Sang Hui Moon, https://orcid.org/0000-0003-1102-8714

Seung-Bum Ryoo, https://orcid.org/0000-0001-6407-0444

Seung-Yong Jeong, https://orcid.org/0000-0003-2726-4850

Kyu Joo Park, https://orcid.org/0000-0002-9134-7426

\section{AUTHORS' CONTRIBUTIONS}

Conceptualization : Ji Won Park. Formal analysis: Young Jin 
Kim, Ji Won Park. Methodology: Young Jin Kim, Ji Won Park. Writing-original draft: Young Jin Kim, Ji Won Park. Writingreview and editing: Young Jin Kim, Ji Won Park, Han-Ki Lim, Yoon-Hye Kwon, Min Jung Kim, Eun Kyung Choe, Sang Hui Moon, Seung-Bum Ryoo, Seung-Yong Jeong, Kyu Joo Park.

\section{CONFLICT OF INTEREST}

None.

\section{FUNDING}

None.

\section{ACKNOWLEDGMENTS}

Assistance provided by Mi Sun Seo and Yoon Suk Song was greatly appreciated. Specially Thanks to Dr. Ah Ram Han, for helpful advice.

\section{REFERENCES}

1) Holzman MD, Eubanks S. Laparoscopic colectomy. Prospects and problems. Gastrointest Endosc Clin N Am 1997;7:525-539.

2) Park SJ, Lee KY, Lee SH. Laparoscopic Surgery for Colorectal Cancer in Korea: Nationwide Data from 2013 to 2018. Cancer Res Treat 2020; 52:938-944.

3) Hur H, Oh CM, Won YJ, Oh JH, Kim NK. Characteristics and Survival of Korean Patients With Colorectal Cancer Based on Data From the Korea Central Cancer Registry Data. Ann Coloproctol 2018;34: 212-221.

4) Cho YB, Lee WY, Yun HR, Lee WS, Yun SH, Chun HK. Tumor localization for laparoscopic colorectal surgery. World J Surg 2007;31: 1491-1495.

5) Acuna SA, Elmi M, Shah PS, Coburn NG, Quereshy FA. Preoperative localization of colorectal cancer: a systematic review and metaanalysis. Surg Endosc 2017;31:2366-2379.

6) Hammond DC, Lane FR, Welk RA, Madura MJ, Borreson DK, Pas- sinault WJ. Endoscopic tattooing of the colon. An experimental study. Am Surg 1989;55:457-461.

7) Miyoshi N, Ohue M, Noura S, et al. Surgical usefulness of indocyanine green as an alternative to India ink for endoscopic marking. Surg Endosc 2009;23:347-351.

8) Lee JG, Low AH, Leung JW. Randomized comparative study of indocyanine green and India ink for colonic tattooing: an animal survival study. J Clin Gastroenterol 2000;31:233-236.

9) Lee SJ, Sohn DK, Han KS, et al. Preoperative Tattooing Using Indocyanine Green in Laparoscopic Colorectal Surgery. Ann Coloproctol 2018;34:206-211.

10) Park JW, Sohn DK, Hong CW, et al. The usefulness of preoperative colonoscopic tattooing using a saline test injection method with prepackaged sterile India ink for localization in laparoscopic colorectal surgery. Surg Endosc 2008;22:501-505.

11) Fu KI, Fujii $T$, Kato $S$, et al. A new endoscopic tattooing technique for identifying the location of colonic lesions during laparoscopic surgery: a comparison with the conventional technique. Endoscopy 2001;33:687-691

12) Trakarnsanga A, Akaraviputh T. Endoscopic tattooing of colorectal lesions: Is it a risk-free procedure? World J Gastrointest Endosc 2011; 3:256-260

13) Nizam R, Siddiqi N, Landas SK, Kaplan DS, Holtzapple PG. Colonic tattooing with India ink: benefits, risks, and alternatives. Am J Gastroenterol 1996;91:1804-1808.

14) Price N, Gottfried MR, Clary E, et al. Safety and efficacy of India ink and indocyanine green as colonic tattooing agents. Gastrointest Endosc 2000;51:438-442.

15) Hwang MR, Sohn DK, Park JW, et al. Small-dose India ink tattooing for preoperative localization of colorectal tumor. J Laparoendosc Adv Surg Tech A 2010;20:731-734.

16) Kim EJ, Chung JW, Kim SY, et al. Autologous blood, a novel agent for preoperative colonic localization: a safety and efficacy comparison study. Surg Endosc 2019;33:1080-1086.

17) Narihiro $S$, Yoshida $M$, Ohdaira $H$, et al. Effectiveness and safety of tumor site marking with near-infrared fluorescent clips in colorectal laparoscopic surgery: A case series study. Int J Surg 2020;80:74-78. 